\title{
A case of rabies in man: some problems in diagnosis and management
}

\author{
S L COHEN, SYLVIA GARDNER, CLAIRE LANYI, J R MCDONALD, H RÉE, P A SOUTHORN, \\ A W WOODRUFF
}

British Medical fournal, 1976, 1, 1041-1042

\begin{abstract}
Summary
A patient who returned from India with a gastrointestinal disturbance subsequently developed the clinical features of rabies. The diagnosis was confirmed by isolation of rabies virus from saliva and the demonstration of rising titres of rabies antibody. He was treated in an intensive care unit, ventilated mechanically, and given rabies antiserum, but cerebral activity ceased and he died after 22 days. His course was marked by numerous bouts of cardiac arrhythmia including complete heart block.

This case indicates the need for vaccination against rabies to be carried out immediately after exposure to a possibly rabid dog since once encephalitis develops a fatal outcome may not be prevented even with intensive medical treatment.
\end{abstract}

\section{Introduction}

Rabies is fortunately rare in Britain: there were only eight cases between 1945 and 1969, and in each case the infection was contracted outside the United Kingdom. ${ }^{1}$ A further two cases were seen in London in 1975. ${ }^{2}$

Rabies is usually fatal, but treatment to support life by intensive care has prolonged life in several patients in whom rabies was proved ${ }^{3}{ }^{4}$ and has resulted in recovery in two patients with probable rabies. ${ }^{56} \mathrm{We}$ report a patient with rabies treated along similar lines who died after 22 days.

\section{Case report}

A 22-year-old Englishman was admitted to the Hospital for Tropical Diseases on 6 June 1975, two days after he had returned from a prolonged stay in India. He complained of one year's intermittent diarrhoea and considerable weight loss over the preceding three months. On examination he was thin and pale, but there were no specific abnormal physical signs. Giardia lamblia was isolated from his stools. Two days later he complained of headache and aching limbs and developed a fever of $39^{\circ} \mathrm{C}$, which resolved within 24 hours.

A diagnosis of rabies was considered on 10 June (hereafter called the first day of illness), when he became hyperactive, agitated, and ataxic and was noted to be retching when attempting to swallow water He then disclosed that he had looked after a sick puppy in a temple in India about six weeks earlier; it had scratched him and had licked the scratches, but there was no evidence of scratch marks or sores. The puppy was alive when the patient left the temple in April 1975,

Intensive Care Unit, University College Hospital, London WC1 6JJ $S$ L COHEN, MB, MRCP, consultant physician

CLAIRE LANYI, MB, BS, house physician

P A SOUTHORN, MB, FFARCS, consultant anaesthetist

Central Public Health Laboratory, Colindale, London NW9

SYLVIA GARDNER, MB, MRCP, consultant virologist

J R MCDONALD, FIMLS, senior technical officer

Hospital for Tropical Diseases, London WC1

H RÉE, MD, DCMT, senior lecturer

A W WOODRUFF, MD, FRCP, director and this was his last known contact with a dog. Strict barrier nursing was instituted and saliva was collected for examination for rabies virus. His condition deteriorated over the next few days, and he behaved in a bizarre fashion in spite of sedation with diazepam. He became increasingly confused and ataxic and complained of difficulty in moving his jaw, breathing, and swallowing.

On the sixth day he became comatose, and a lumbar puncture showed clear cerebrospinal fluid (CSF) with a protein content of $0.5 \mathrm{~g} / \mathrm{l}$. Later that day he had a cardiorespiratory arrest. After resuscitation he was transferred to the intensive care unit at University College Hospital. He was suffering repeated inspiratory spasms triggered by any stimulation of the head and neck. These spasms were characterised by descent of the larynx and repeated contractions of the diaphragm and all the inspiratory muscles. Hypersalivation was noted. He was afebrile, the pulse rate was $96 /$ minute, and the electrocardiograph (ECG) monitor showed sinus tachycardia. His blood pressure was $110 / 80 \mathrm{~mm} \mathrm{Hg}$. Widespread crepitations were heard over the lung fields and chest $x$-ray examination confirmed bilateral inhalation pneumonia. The pupils were equal and reacted to light and the optic discs were normal. All tendon reflexes were absent, but the plantar responses were flexor. Haemoglobin was $12 \cdot 1 \mathrm{~g} / \mathrm{dl}$ and white cell count $2.8 \times 10^{9} / 1\left(2800 / \mathrm{mm}^{3}\right)$. Blood urea and electrolyte levels and liver function test results were normal.

Throughout his stay in the intensive care unit he was ventilated on a Cape ventilator, on which his $\mathrm{PaO}_{2}$ was kept at around $13.3 \mathrm{kPa}$ $(100 \mathrm{~mm} \mathrm{Hg})$ and the $\mathrm{PaCO}_{2}$ at $5.3 \mathrm{kPa}(40 \mathrm{~mm} \mathrm{Hg})$. To control his spasms and to settle him on the ventilator he required hourly intravenous administration of up to $10 \mathrm{mg}$ diazepam and frequent doses of pancuronium $2-4 \mathrm{mg}$. Atropine $0.6 \mathrm{mg}$ four-hourly was given in an attempt to reduce the volume of his salivary secretions. After a test dose he was given 3000 units of horse antirabies serum (40 IU/ $/ \mathrm{kg}$ ). Because he had an inhalation pneumonia he was given ampicillin and cloxacillin and dexamethazone $4 \mathrm{mg}$ six-hourly. All vital signs were monitored including ECG and central venous pressure.

He was isolated, and all staff in contact with him wore gowns, gloves, boots, hats, and masks and protective facial visors. As a precaution they were given human diploid cell culture rabies vaccine.

On the seventh day he had a transient cardiac arrest. By the eighth day the pneumonia had cleared but otherwise his condition was unchanged. $\mathrm{He}$ was given a transfusion of rabies immune human plasma containing about 8000 international units of antirabies antibody and also $2 \mathrm{ml}$ of duck embryo rabies vaccine on that day and the next.

On the ninth day he had a gastrointestinal bleed; four units of whole blood were transfused, and the dexamethasone was stopped. Various cardiac arrhythmias were observed, including atrial and ventricular ectopics, with runs of atrial flutter and brief periods of second degree and complete heart block (see fig).

By the 11th day of his illness the spasms had decreased in frequency and severity. His sedation was reduced and his conscious level improved; he followed objects and made attempts to speak. He also had a spike fever of $39^{\circ} \mathrm{C}$, which rapidly settled. On the 13th day a vesicular rash was noted on the genitalia from which herpes simplex was isolated. He had a further transient hypotensive episode, although he was in sinus rhythm with a rate of 90 /minute. On the next day a tracheostomy was performed and over that day his conscious level deteriorated. By the 15th day his pupils had become permanently fixed and dilated and he was quite unresponsive, requiring neither sedation nor muscle relaxants. An electroencephalogram on the 16 th day showed basic theta activity intermingled with occasional delta activity.

Complete heart block with a rate of 40 /minute was recorded on the 15th day and was controlled with an infusion of isoprenaline $5 \mu \mathrm{g} / \mathrm{min}$. Episodes of variable heart block and hypotension continued, and on the 17th day his plasma creatine phosphokinase reached a maximum of $211 \mathrm{IU} / \mathrm{l}$ (normal 3-40 IU/1). His ECG on the 18th day showed changes suggestive of pericarditis as well as complete heart block (see fig); the heart block again responded to isoprenaline. Frequent arrhythmias recurred; on the 22 nd day he was again in complete heart block, 


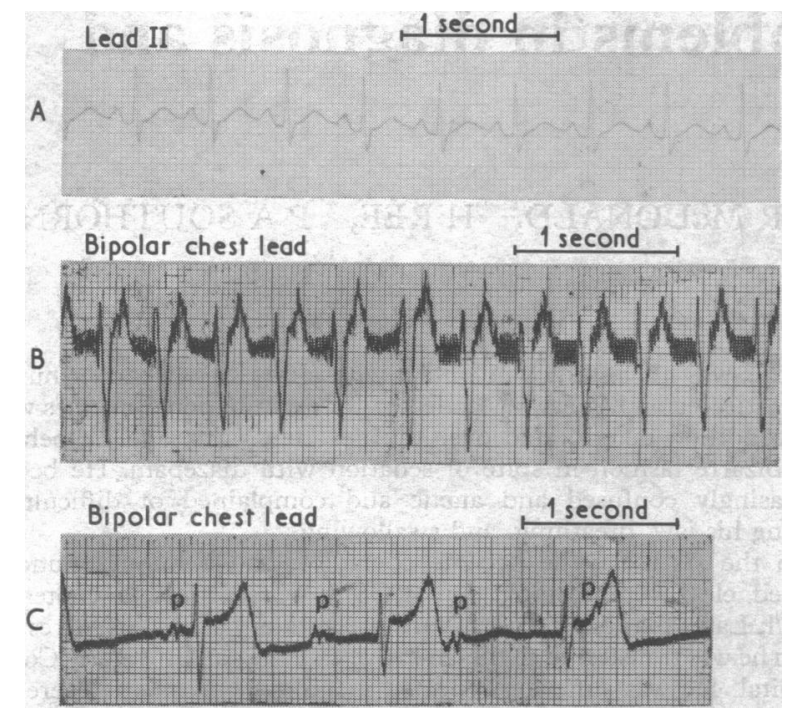

Serial electrocardiograms showing (A) sinus tachycardia, rate $120 / \mathrm{min}$; (B) atrial tachycardia, rate $165 / \mathrm{min}$; (C) complete heart block, atrial rate $66 / \mathrm{min}$, ventricular rate $60 / \mathrm{min} ; \mathrm{S}-\mathrm{T}$ segment elevation concave upwards is typical of acute pericarditis.

which was not controllable with isoprenaline. On that day he had a cardiac arrest and died. Throughout his last week of life he remained totally unresponsive with fixed dilated pupils.

\section{VIROLOGICAL STUDIES}

Examination of saliva and CSF samples for rabies virus was undertaken using the standard laboratory techniques recommended by the World Health Organisation. ${ }^{7}$ Specimens were obtained as shown in the table.

After an incubation period of 15 days mice inoculated with saliva obtained on the 8th day of illness showed signs suggestive of rabies. Negri bodies were seen in mouse brain impression smears and rabies antigen was shown by immunofluorescence. Rabies virus was also isolated from saliva collected on the 11th day but not from saliva obtained on the 2 nd day or CSF collected on the eighth and 14th days.

Serum samples taken during the course of the illness were examined for rabies antibody by the indirect fluorescent antibody technique. Actively produced rabies antibody was first shown on the 13th day and the titres increased to $1 / 1000$ by the 22nd day. Complementfixing antibody was not shown in any of the sera examined.

\section{Discussion}

The patient presented several of the well-known clinical features and complications of rabies. ${ }^{4} 589$ The insidious onset of increasing confusion and ataxia has been described in many cases of rabies. The diagnosis was complicated by the patient's admission with an unrelated gastrointestinal disturbance. The story of being scratched by a dog was obtained only by direct questioning four days after admission and even then it was by no means certain that the dog was either rabid or the source of the infection. The subsequent development of hydrophobia and hypersalivation followed by coma and flaccid paralysis were classic manifestations of rabies. Degeneration of peripheral nerves was seen in another recent British case." The diagnosis was later established beyond doubt by the isolation on two separate days of rabies virus from saliva and supported by the demonstration of rising titres of rabies antibody.

The major complications in this case were cardiac. The patient developed various arrhythmias, which occurred with increasing frequency. Myocarditis is a well-recognised complication of rabies, ${ }^{810}$ but this patient's ECGs were suggestive of both myocarditis and pericarditis, as shown in the figure. No clinical signs of pericarditis or pericardial effusion were detected. For this reason further investigation-for example, by echocardiography - was not performed. The insertion of a pacemaker was repeatedly considered, but initially his heart block could be controlled with atropine and isoprenaline and by the time this was no longer effective there was no clinical evidence of a surviving brain.

Since rabies antibody does not develop until late in the course of the illness this patient was given horse antirabies serum and subsequently human rabies immune plasma. It is difficult to devise a rational plan of immunotherapy, as the role of antibody in the pathogenesis of the illness is not defined. ${ }^{5}$ The final cerebral deterioration in this patient appeared to coincide with the development of actively produced antibody.

Hattwick et al ${ }^{5}$ suggested that the treatment of clinical rabies must rely on "aggressive" supportive care. Their patient most probably had rabies, although the virus was not isolated and the course of duck embryo vaccine given immediately after the bite may well have contributed to the recovery. No further reports of recovery from clinically diagnosed rabies have appeared since that case. ${ }^{4}$ Patients with proved rabies ${ }^{311}$ have recently survived for long periods, and a patient with probable rabies has survived but with severe neurological sequelae. ${ }^{6}$

Our case underlines the importance of vaccination against rabies being performed immediately after exposure to a possible rabid animal if clinical rabies is to be prevented. The trivial nature of the incident leading to infection in our patient suggests that only a pre-exposure course of vaccination could have averted the fatal outcome.

We thank the sisters and nurses of the intensive care unit for their devoted care of this patient. We would also like to thank Dr D A Warrell for his helpful advice on the general management and Dr A Hollman for his advice on the cardiac problems.

Requests for reprints should be addressed to Dr S L Cohen, Intensive Care Unit, University College Hospital, London WC1E $6 \mathrm{JJ}$.

\section{References}

${ }^{1}$ Macrae, A D, Lancet, 1969, 2, 1415.

2 Maton, P N, Pollard, J D, and Newsom Davis, J, British Medical fournal, 1976, 1, 1038.

${ }^{3}$ Rubin, R H, et al, fournal of Infectious Diseases, 1970, 122, 318

4 British Medical fournal, 1975, 3, 721.

${ }^{5}$ Hattwick, M A W, et al, Annals of Internal Medicine, 1972, 76, 931.

${ }^{6}$ Barboza, J J, et al, Vigilencia Epidemiologica, 1972, 4, 90.

' Kaplan, M M, and Koprowski, H, (editors), Laboratory Techniques in Rabies, 3rd edn. WHO. Geneva, World Health Organisation, 1973.

${ }^{8}$ Cheetham, H D, et al, Lancet, 1970, 1, 921.

${ }^{9}$ Bhatt, D R, et al, American Fournal of Diseases of Children, 1974, 127, 862.

${ }_{10}$ Ross, E, and Armentrout, S A, New England fournal of Medicine, 1962, 266, -1087.

${ }^{11}$ Emmons, R W, et al, Intervirology, 1973, 1, 60.

Virological studies on patient with clinical rabies

\begin{tabular}{|c|c|c|c|c|c|c|c|c|c|c|c|c|c|c|c|}
\hline Day: & 2 & 6 & 7 & 8 & 9 & 11 & 13 & 14 & 15 & 16 & 17 & 18 & 19 & 21 & 22 \\
\hline $\begin{array}{l}\text { Specimen } \\
\text { Rabies virus } \\
\text { Serum rabies } \\
\text { antibody titres }\end{array}$ & $\begin{array}{c}\text { Saliva } \\
<\overline{1} / 5\end{array}$ & $\begin{array}{l}\text { Horse anti- } \\
\text { rabies serum }\end{array}$ & $\begin{array}{l}\text { Duck embryo } \\
\text { vaccine } \\
(2 \mathrm{ml})\end{array}$ & $\begin{array}{c}\text { Duck embryo } \\
\text { vaccine } \\
\text { (2ml), rabies } \\
\text { immune } \\
\text { plasma } \\
\text { Saliva, CSF } \\
++-\end{array}$ & $\begin{array}{l}\text { Duck embryo } \\
\text { vaccine } \\
\quad(2 \mathrm{ml}) \text {, blood } \\
\text { transfusion } \\
<1 / 5\end{array}$ & $\begin{array}{l}\text { Saliva } \\
+\underset{+1 / 5}{ }\end{array}$ & Trace & $\begin{array}{l}\text { CSF } \\
1 / 10\end{array}$ & $1 / 80$ & $1 / 160$ & $>1 / 160$ & $1 / 400$ & $1 / 800$ & $1 / 1000$ & $1 / 1000$ \\
\hline
\end{tabular}

